"Kraft" pulp for wrapping and packaging. It is said that the requirements of the raw materials for such processes are less exacting in quality and quantity than in the case of dissolving pulp, which is largely used in the manufacture of artificial fibre.

Progress continued in the dedication of woodlands, and during the year the area dedicated increased from 225,000 acres to 343,000 acres.

\section{E. P. StebBing}

\section{AUSTRALIAN ATOMIC ENERGY COMMISSION}

A

REPORT of the work of the Australian Atomic Energy Commission since its establishment in 1953 is outlined in an article by Prof. J. F. Baxter, vice-chancellor of the New South Wales University of Technology, in the Australian Journal of Science (17, No. 5, 151; 1955). Details are given of the initial stages which led up to the establishment of the Commission, its composition and its two main fields of activity, namely, that related to the discovery and production of uranium and that related to the development of the use of atomic energy for industrial and other purposes. In surveying what the Commission has accomplished since its establishment, Prof. Baxter mentions the completion of the plant for the mining of uranium ore at Rum Jungle, which was set in motion by the Prime Minister on September 17, 1954, and of the opening of the Radium Hill mine and concentrator during 1954. A modern treatment plant at Port Pirie was expected to be completed in the near future.

In regard to its responsibilities for the development of uses for atomic energy, the Commission decided to try to obtain access to the large amount of secret information accumulated by Great Britain, the United States and Canada, and to work in partnership with these powers. After various discussions and visits by prominent scientific workers both from Great Britain to Australia and vice versa, Britain offered to give to Australia its accumulated knowledge arising from its industrial atomic-energy programme and, in addition, agreed to enter into a co-operative research programme with Australia whereby the Australian Atomic Energy Commission would set up a research and development organization in Australia while Britain would provide facilities for the training of Australian scientists and engineers in the various British atomic-energy establishments. Accordingly, a Scientific Advisory Committee, consisting of Prof. M. Oliphant, Prof. L. H. Martin, Dr. F. W. G. White, Prof. R. Myers, Prof. T. G. Hunter, Prof. J. S. Anderson, Mr. V. Brain and Prof. J. P. Baxter (chairman), was appointed by the Commission, and a comprehensive group of laboratories has been constructed and equipped on a site some twenty miles south of Sydney.

A large research reactor of a modern type, designed to give a high neutron flux, is to be installed; and $\mathbf{a}$ scientific staff of fifty senior scientists and about three hundred other personnel are to be recruited. The chief of research and development is Prof. C. N. Watson-Munro ; the chief engineer and doputy chicf of research, Prof. G. C. J. Dalton; and Dr. G. L. Miles and Mr. K. F. Alder, leaders of tho chemistry and metallurgy departments, respectively. In addition, the initiation and support, on a very large scale, of research and development work in the Australian universities is planned by the Commission, and special facilities for research and advanced training for engineers and scientists from universities and industry in its laboratories at Sydney are to be provided. Finally, a Business Advisory Group has been formed by the Minister for Supply in order that the Commission and leaders of industry may confer closely and regularly on atomic energy matters.

\section{THE TUBER-BEARING SPECIES OF SOLANUM}

$\mathrm{M}$

UCH has been written of the potato, its South American origin, its introduction into Europe, its many varietal forms and its taxonomy. J. G. Hawkes (Proc. Linn. Soc., 166, 1 and 2, 97; 1956) has now contributed a comprehensive and critical taxonomic study of the tuber-bearing species of Solanum, special attention being paid to $S$. tuberosum and the tetraploid species complex. In the designation of a nomenclatural type for $S$. tuberosum the early descriptions of C. Bauhin, Clusius and others are mentioned in relation to those of Linnaeus. Fvidence is brought forward to show that one of the three specimens in the Linnean Herbarium labelled as $S$. tuberosum may be considered as the lectotype. It is then pointed out that Linnaeus's description, made when one species of tuberiferous Solanum alone was known, could equally well be taken as referring to some 80 per cent of the wild species described later. A new description has therefore been drawn up with attempts to include the complete range of variability of $S$. tuberosum under modern concepts, and this is followed by reference to the main features that distinguish it from other potato species.

The views of the Russian taxonomists on the subdivision of the cultivated tetraploid potato into two distinct species are outlined. The criticisms levelled at these views show that it is impossible to separate the cultivated tetraploids into more than one species and that the weed tetraploids previously described as distinct should also be included within $S$. tuberosum. Experimental data support these views.

An analysis of the difference between the Andean and Chilean South American potatoes makes it possible to recognize two subspecies, namely, $(a)$ subspecies andigena from the mountains of Venezuela, Colombia, Ecuador, Peru, Bolivia and north Argentina; (b) subspecies tuberosum from Europe and South Chile. That the European and Chilean potatoes aro included under the same subspecific name does not imply that the former were derived from the latter ; but that each evolved under similar environmental conditions from original Andean stocks.

As to the origin of the tetraploid potato, it can be considered as an autotetraploid, but may have been formed as an amphidiploid hybrid between two species the genomes of which were not quite identical.

The conclusion is that $S$. tuberosum was derived from an already cultivated diploid species and not directly from a wild one. Indeed, it seems probable that the cultivated potato $S$. stenotomum or a precursor of this species was the original diploid ancestor of our tetraploid potato. There is also evidence that the weed diploid S. sparsipilum may also have played some part in the formation of $S$. tuberosum, though cytological opinion is more strongly in favour of S. stenotomum. 